Article

\title{
Acid-Catalysed Conversion of Saccharides into Furanic Aldehydes in the Presence of Three-Dimensional Mesoporous Al-TUD-1
}

\author{
Sérgio Lima ${ }^{1}$, Margarida M. Antunes ${ }^{1}$, Auguste Fernandes ${ }^{2}$, Martyn Pillinger ${ }^{1}$, \\ Maria Filipa Ribeiro ${ }^{2}$ and Anabela A. Valente ${ }^{1, *}$
}

1 Department of Chemistry, CICECO, University of Aveiro, 3810-193 Aveiro, Portugal;

E-Mails: sergiolima@ua.pt (S.L.); margarida.antunes@ua.pt (M.M.A.); mpillinger@ua.pt (M.P.)

2 Institute for Biotechnology and Bioengineering, Centre for Biological and Chemical Engineering, Instituto Superior Técnico, Av. Rovisco Pais, 1049-001 Lisboa, Portugal;

E-Mails: auguste.fernandes@ist.utl.pt (A.F.); filipa.ribeiro@ist.utl.pt (M.F.R.)

* Author to whom correspondence should be addressed; E-Mail: atav@ua.pt;

Tel.: +351-234-370-603; Fax: +351-234-401-470.

Received: 13 April 2010; in revised form: 24 May 2010 / Accepted: 26 May 2010 /

Published: 28 May 2010

\begin{abstract}
The one-pot acid-catalysed conversion of mono/di/polysaccharides (inulin, xylan, cellobiose, sucrose, glucose, fructose, xylose) into 2-furfuraldehyde (FUR) or 5-hydroxymethylfurfural (HMF) in the presence of aluminium-containing mesoporous TUD-1 (denoted as Al-TUD-1, $\mathrm{Si} / \mathrm{Al}=21$ ), at $170{ }^{\circ} \mathrm{C}$ was investigated. Xylose gave $60 \%$ FUR yield after $6 \mathrm{~h}$ reaction; hexose-based mono/disaccharides gave less than 20\% $\mathrm{HMF}$ yield; polysaccharides gave less than $20 \mathrm{wt} \%$ FUR or HMF yields after $6 \mathrm{~h}$. For four consecutive $6 \mathrm{~h}$ batches of the xylose reaction in the presence of Al-TUD-1, the FUR yields achieved were similar, without significant changes in $\mathrm{Si} / \mathrm{Al}$ ratio.
\end{abstract}

Keywords: solid acid; mesoporous materials; biomass valorisation; 2-furfuraldehyde; 5hydroxymethylfurfural 


\section{Introduction}

The conversion of renewable biomass resources into non-petroleum derived fuels and chemicals is becoming increasingly attractive as a way to avoid intensification of global warming and diversify energy sources [1-4]. Several low-cost kinds of plant biomass may be utilised, such as agricultural and forest waste and surpluses, plants grown on arid land, and aquatic plants. The major components of plant-derived biomass are carbohydrates, which may be converted into a number of valuable platform compounds, such as 2-furfuraldehyde (FUR) and 5-hydroxymethylfurfural (HMF). FUR and HMF may be produced via acid-catalysed hydrolysis of di/oligo/polysaccharides into the respective monosaccharides, followed by cyclodehydration of the latter. FUR is produced on an industrial scale (commonly using $\mathrm{H}_{2} \mathrm{SO}_{4}$ as the catalyst) for a plethora of applications [5,6]. To the best of our knowledge, HMF has not reached industrial scale production.

Efforts have been made over the past few years to develop stable, recyclable, solid Brønsted and/or Lewis acids based on inorganic oxides for the conversion of saccharides into FUR and HMF [7-15]. Of the studied catalysts, microporous zeolites or zeotype materials are quite promising [7-11]. However, the transformation of relatively bulky saccharides may be hindered in a microporous structure, and hence the use of mesoporous aluminosilicates may be preferable [16]. In 1992 Kresge et al. reported the synthesis of ordered mesoporous aluminosilicates using surfactants as templates [17]. The so-called M41S materials possess high specific surface areas and pore volumes, and uniform but controllable pore sizes in the range of $2-10 \mathrm{~nm}$, which makes them interesting candidates as catalysts or catalyst supports. Many other types of mesoporous materials have since been described, most of which are prepared using surfactants or polymers as structure-directing agents. Economic concerns have motivated the search for low-cost, non-surfactant templating routes to mesoporous materials. An important discovery was the straightforward synthesis of the three-dimensional spongelike mesoporous (siliceous) oxide TUD-1, using either triethanolamine or tetraethyleneglycol as organic templates [18]. The purely siliceous TUD-1 may be furnished with Brønsted and Lewis acidity by the incorporation of metals such as Al into the framework via a one-pot procedure based on the solgel technique [19-24]. The high specific surface area, pore volume and width of TUD-1 and related materials, coupled with the 3-D channel system, may facilitate diffusion and promote the access of bulky reagents to active sites.

In the present work, aluminium-containing mesoporous TUD-1 (denoted as Al-TUD-1) has been investigated for the first time as a solid acid catalyst in the acid-catalysed conversion of saccharides into FUR and HMF, at $170{ }^{\circ} \mathrm{C}$. The substrates used were xylose, fructose and glucose as typical monosaccharides, sucrose and cellobiose as examples of disaccharides, and xylan (a polymer composed mainly of xylose) and inulin (a polymer of fructose) as polysaccharides.

\section{Results and Discussion}

\subsection{Synthesis and characterisation of the catalyst}

Al-TUD-1 was prepared as described previously using aluminium(III) isopropoxide and tetraethylorthosilicate as the Al and Si sources, respectively, and triethanolamine as the template [20]. After calcination, elemental analysis indicated a $\mathrm{Si} / \mathrm{Al}$ ratio of 21 , which is close to the ratio of 25 used 
in the synthesis gel. The powder X-ray diffraction (XRD) pattern of Al-TUD-1 shows only one broad peak at low angle ( $\mathrm{ca} .1 .4^{\circ} 2 \theta$ ) and a very broad peak centred around $24^{\circ} 2 \theta$ (Figure 1), indicating that the material is amorphous, but has the characteristics of a mesostructured material $[19,21,24,25]$. No evidence of crystalline alumina or other phases can be detected in the pattern.

Figure 1. Powder XRD pattern of Al-TUD-1.

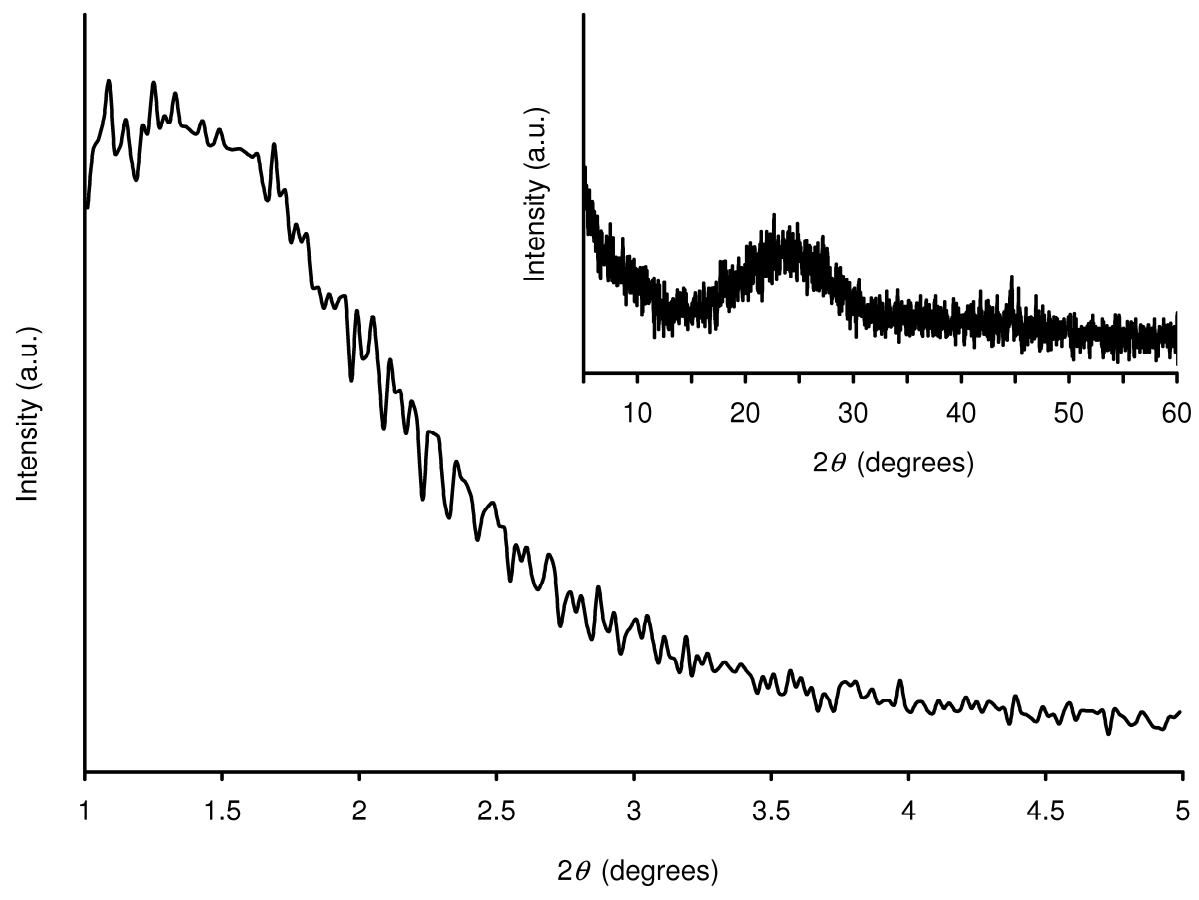

Al-TUD-1 exhibits a type IV $\mathrm{N}_{2}$ adsorption isotherm with a $\mathrm{H} 2$ hysteresis loop (Figure 2), which is consistent with the presence of a disordered mesoporous material with an interconnected (worm-like) pore network [22,26-28].

Figure 2. $\mathrm{N}_{2}$ adsorption-desorption isotherms at $-196^{\circ} \mathrm{C}$ of Al-TUD-1.

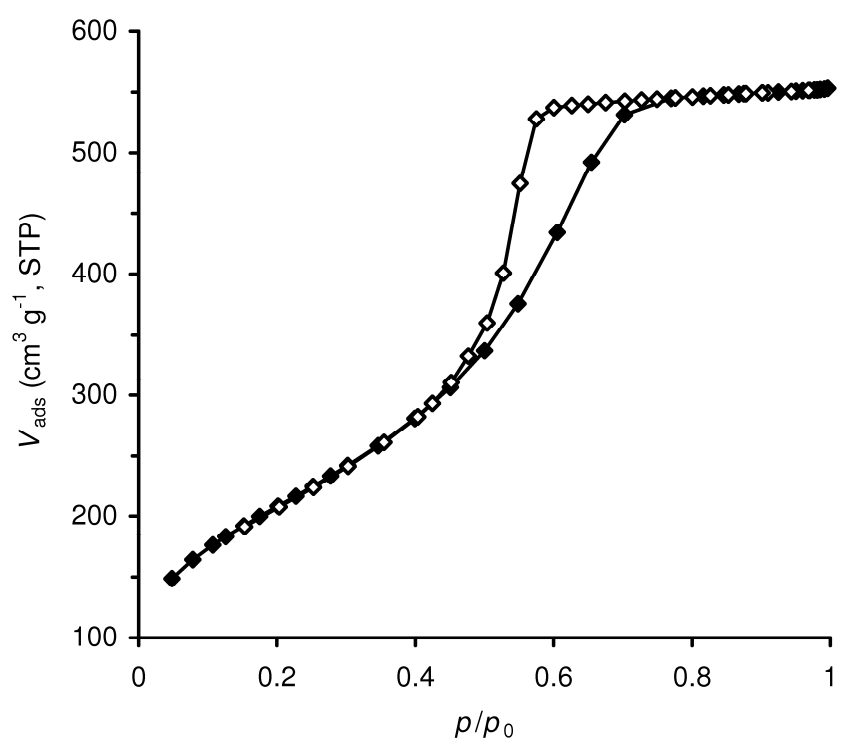


The capillary condensation in the mesopores occurs in the relative pressure range of about 0.5 to 0.7 , above which the adsorption branch levels off and no more adsorption takes place in the higher relative pressure region (external surface area is negligible). Similar results were reported previously for purely siliceous and metal-incorporated TUD-1 samples [19,21,22,29].

The isotherm for Al-TUD-1 gave a BET specific surface area of $757 \mathrm{~m}^{2} \mathrm{~g}^{-1}$, and average pore diameters of $4.3 \mathrm{~nm}$ (calculated from the adsorption branch, using the $\mathrm{BJH}$ method) and $3.9 \mathrm{~nm}$ (calculated from the desorption branch). SEM analysis of Al-TUD-1 showed particles with an uneven shape and size (Figure 3).

Figure 3. Representative SEM image of Al-TUD-1.

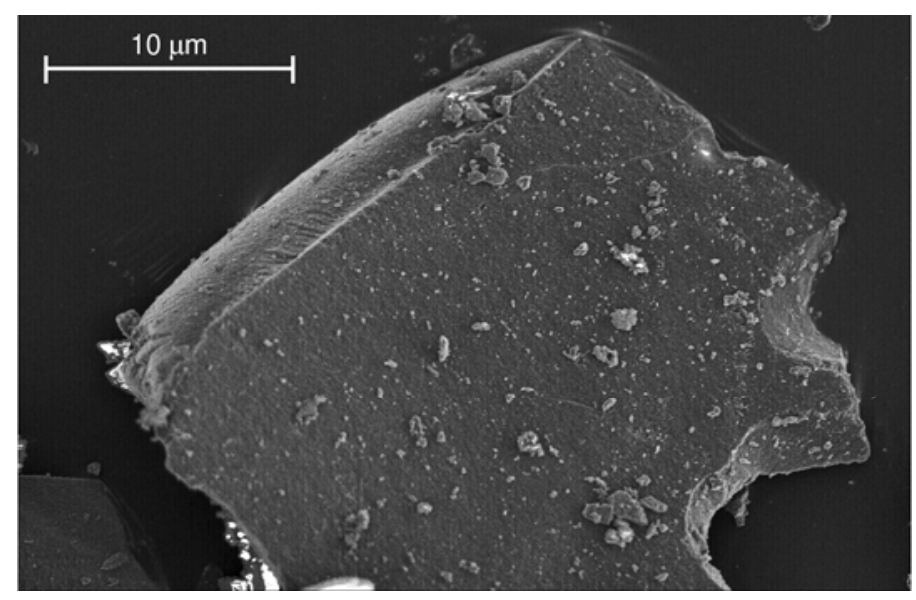

The nature of Al in Al-TUD-1 was investigated by using ${ }^{27} \mathrm{Al}-\mathrm{NMR}$ spectroscopy (Figure 4). The spectrum exhibits a strong resonance at $\delta=53 \mathrm{ppm}$, which can be assigned to tetrahedrally coordinated (structural) aluminium species. A high-field signal at $\delta=0 \mathrm{ppm}$ is attributed to hexacoordinate Al centres. The spectrum is very similar to that described previously for Al-TUD-1 with $\mathrm{Si} / \mathrm{Al}=30$ prepared using triethanolamine as the template [30].

Figure 4. ${ }^{27} \mathrm{Al}$ MAS NMR spectrum of Al-TUD-1.

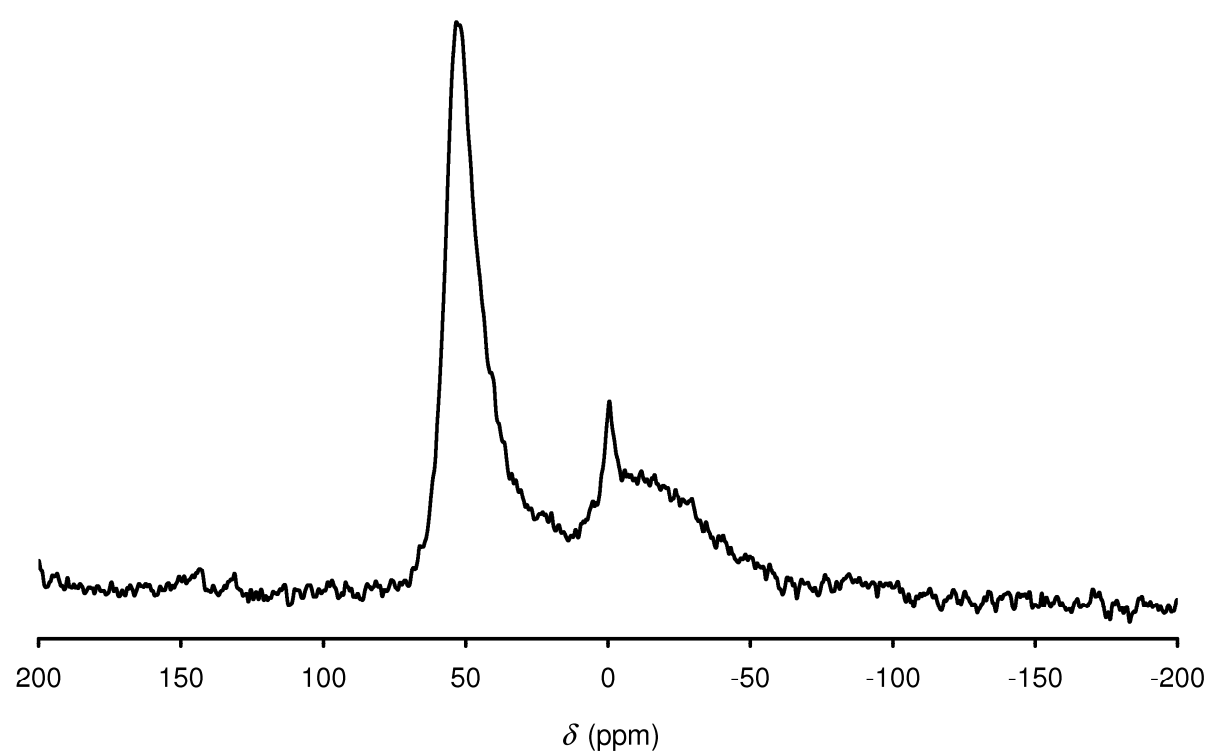


The Brønsted (B) and Lewis (L) acid properties of Al-TUD-1 were quantified by adsorption of pyridine followed by FTIR. Pyridine was chosen as the basic probe since its critical dimension of $c a$. $0.65 \mathrm{~nm}$ [31] is comparable with the size of the xylose molecule. The sample showed both $\mathrm{L}$ and B sites interacting with pyridine after outgassing at $150{ }^{\circ} \mathrm{C}$ : $[\mathrm{B}]=59 \mu \mathrm{mol} \mathrm{g}^{-1}$, [L] $=138 \mu \mathrm{mol} \mathrm{g}^{-1}$. Although the L sites are probably due to defective framework and/or extra-framework Al species, we cannot exclude the possibility that $\mathrm{L}$ sites may also arise from tetrahedral aluminium. Indeed, in a study of the adsorption of pyridine on mesoporous aluminosilicate SBA-15 molecular sieves, Luan and Fournier reported that the tetrahedral aluminium centres contributed only to Lewis acidity [32]. Normally, in crystalline zeolite materials, tetrahedral aluminium is expected to form bridging hydroxyl groups $(\mathrm{Si}-\mathrm{OH}-\mathrm{Al})$, contributing to Brønsted acidity. Luan and Fournier reasoned that tetrahedral aluminium in mesoporous aluminosilicates with amorphous pore walls could contribute to Lewis acidity due to crystallographic disorder at the atomic level. For Al-TUD-1, at $350{ }^{\circ} \mathrm{C}$ pyridine desorbed more easily from the $\mathrm{B}$ sites than from the $\mathrm{L}$ sites. Thus, the ratio moderate + strong to total Brønsted sites $\left([\mathrm{B}]_{350} /[\mathrm{B}]_{150}\right)$ was 0.02 , indicating that most of the sites are of a rather weak nature, while the Lewis ratio $\left([\mathrm{L}]_{350} /[\mathrm{L}]_{150}\right)$ was 0.61 . Nevertheless, it is worth mentioning that the number of Brønsted sites in Al-TUD-1 may be underestimated since pyridine is a weak base (compared with, for example, ammonia) and may not be able to deprotonate the weaker sites present in the sample (nevertheless, ammonia may lead to an overestimate of the effective number of acid sites because of its smaller molecular dimensions in comparison to the saccharide molecules) [33].

\subsection{Catalysis}

\subsubsection{General considerations}

The liquid phase conversion of saccharides under nitrogen in the presence of Al-TUD-1 was investigated at $170{ }^{\circ} \mathrm{C}$ using a water-toluene biphasic solvent system. Unless otherwise specified, product yields are reported in mol \%. FUR and HMF selectivities are improved by using an organic extracting solvent since the reaction of the saccharides takes place in the aqueous phase, and the product FUR or HMF is partially transferred into the organic phase [34,35]. The acid hydrolysis of di/polysaccharides gives monosaccharides; dehydration of pentoses and hexoses gives FUR and HMF, respectively, via the elimination of three water molecules per molecule of monosaccharide (Figure 5) $[5,36,37]$.

Catalyst stability tests were carried out for Al-TUD-1 by performing four consecutive $6 \mathrm{~h}$ batches of the xylose reaction. After each run, the catalyst was separated, washed with methanol, and activated at $350{ }^{\circ} \mathrm{C}$ for $3 \mathrm{~h}$ with a heating rate of $1{ }^{\circ} \mathrm{C} \mathrm{min}^{-1}$. Conversions of xylose (87-96\%) and FUR yields $(56-60 \%)$ in recycling runs were quite similar (Figure 6). The $\mathrm{Si} / \mathrm{Al}$ mole ratio of the recovered solid was 22, which is comparable to that of the fresh catalyst (experimental error of the ICP-OES analyses for $\mathrm{Al}$ and $\mathrm{Si}$ is 6.0 and 7.2\%, respectively), suggesting that Al-TUD-1 is fairly stable under the reaction conditions used. 
Figure 5. Simplified representation of the acid hydrolysis and dehydration of saccharides into FUR and HMF.

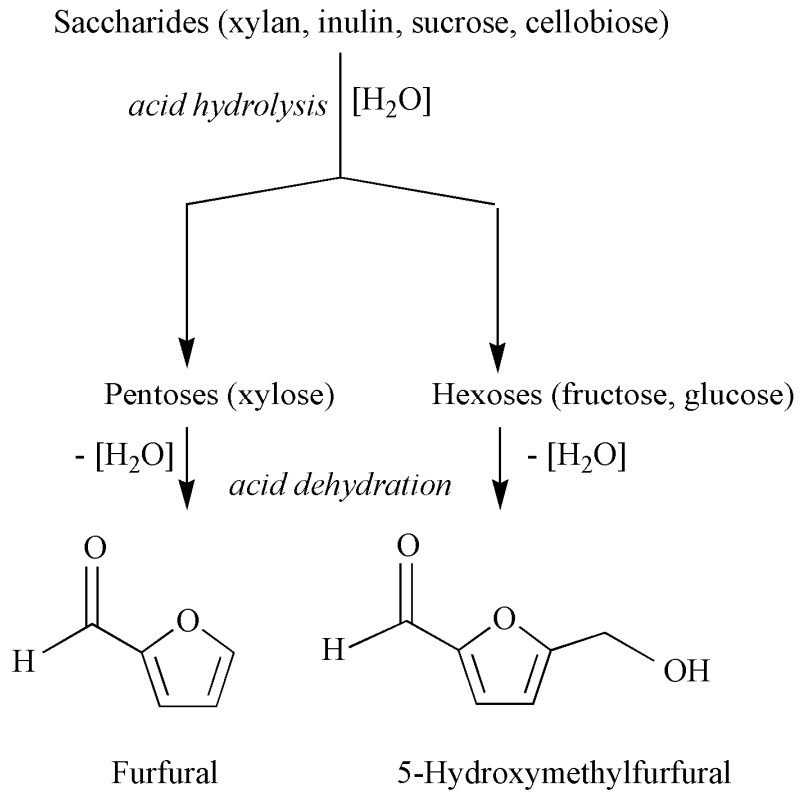

Figure 6. Reaction of xylose in the presence of Al-TUD-1 at $170^{\circ} \mathrm{C}$ (four consecutive $6 \mathrm{~h}$ batches).

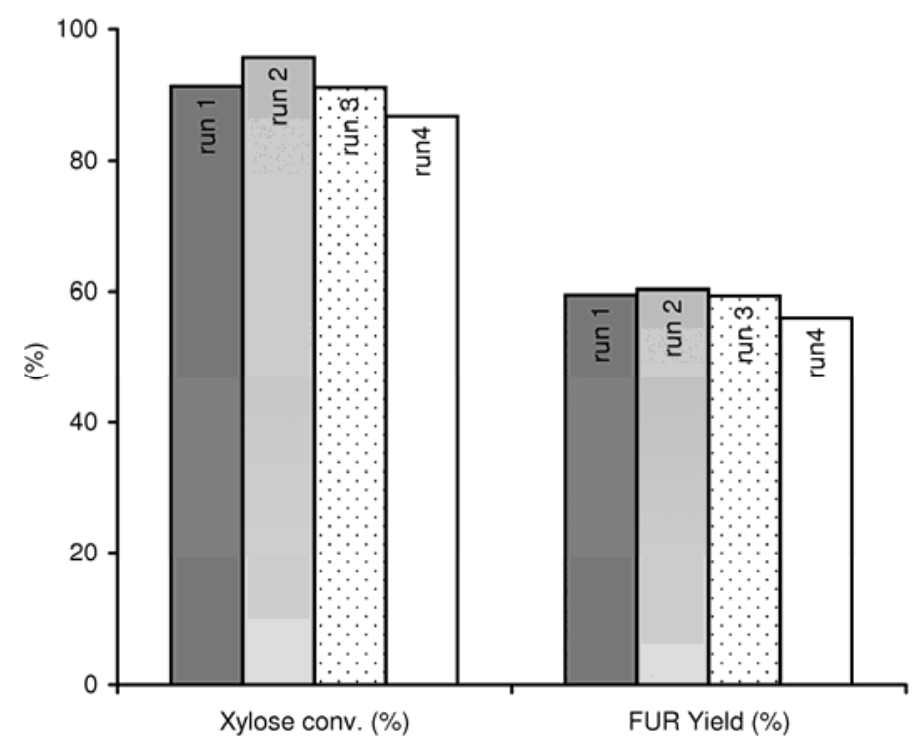

2.2.2. Pentose-based carbohydrate feedstock

The reaction of xylose in the presence of Al-TUD-1 gave 56\%/60\% FUR yield at $4 \mathrm{~h} / 6 \mathrm{~h}$ (Figure 7A). These results compare favourably with those reported for a delaminated zeolite $(\mathrm{Si} / \mathrm{Al}=29)$ obtained by swelling and ultrasonication of a layered precursor of $\mathrm{Nu}-6(2)$ (46\% FUR yield [38]), $\mathrm{H}$-mordenite zeolite ( $\mathrm{Si} / \mathrm{Al} \sim 6,34 \%$ at $4 \mathrm{~h}$ [38]), and microporous silicoaluminophosphates (FUR yields of $41-48 \%$ for SAPO-11 at $6 \mathrm{~h}$ [11]), used as solid acid catalysts in the same reaction, under similar conditions. 
Figure 7. Reaction of xylose (A: $(\bullet)$ conversion; $(\times)$ FUR yield), and reaction of xylan (B: $(\bullet)$ xylose yield; $(\times)$ FUR yield), in the presence of Al-TUD-1 at $170{ }^{\circ} \mathrm{C}$.
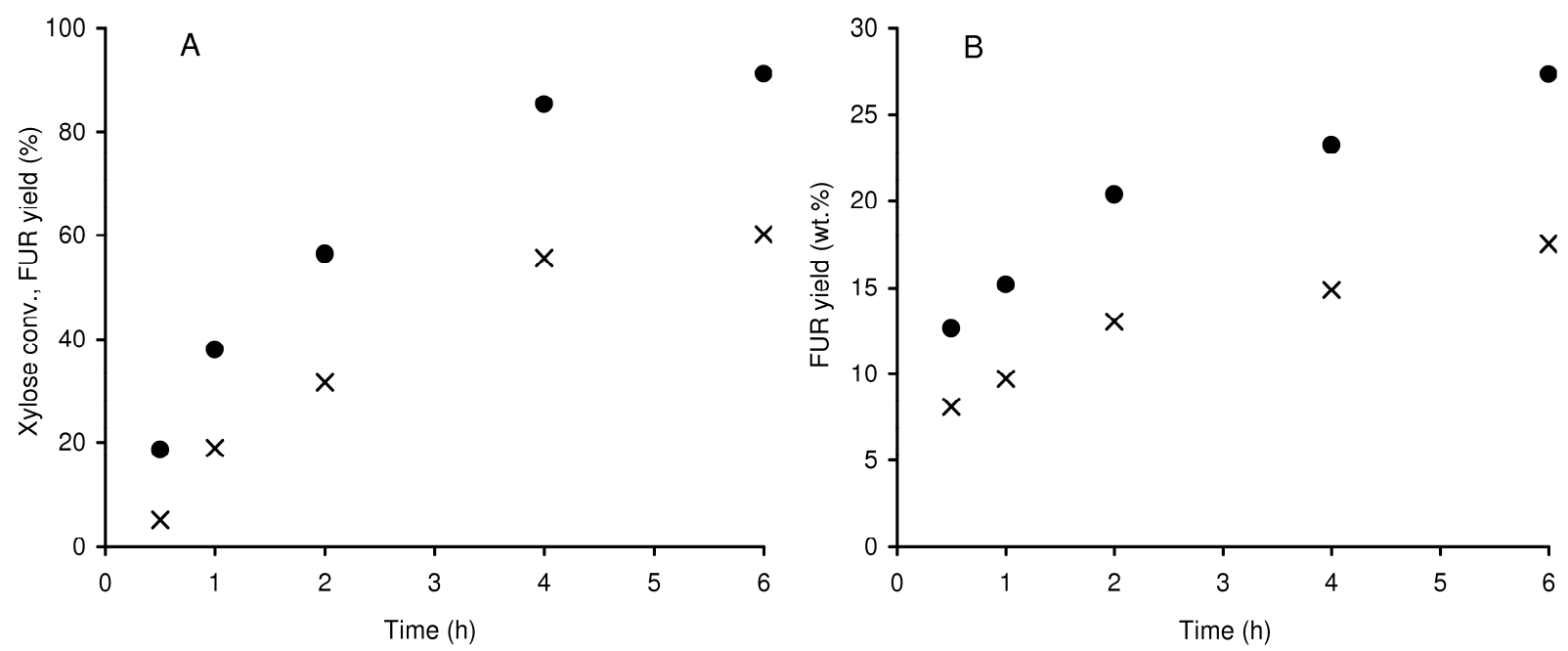

The conversion of xylose is $91 \%$ at $6 \mathrm{~h}$, indicating that by-products amount to $31 \%$ yield. During the reaction of xylose the initially colourless water/toluene phases turned yellow-orange and the white powdered catalyst turned brown, suggesting the presence of organic by-products. However, significant amounts of organic by-products were not detected by chromatographic techniques (HPLC of the aqueous phase and GC-MS of the toluene phase). Possibly, soluble oligo/polymeric products are formed. According to the literature, by-products may be formed via fragmentation and/or condensation reactions involving intermediates and FUR [5,39]. The one-pot conversion (hydrolysis and dehydration) of xylan in the presence of Al-TUD-1 gave xylose (hydrolysis product) and FUR in increasing amounts reaching 27 and $18 \mathrm{wt} \%$ yield at $6 \mathrm{~h}$ (Figure 7B); the theoretical FUR yield is ca. $73 \mathrm{wt} \%$.

\subsubsection{Hexose-based carbohydrate feedstock}

Figure 8 shows the catalytic results obtained for the reactions of fructose and glucose in the presence of Al-TUD-1, at $170{ }^{\circ} \mathrm{C}$. For both hexoses, the isomers glucose, fructose and mannose were simultaneously present, with the mannose yield always being less than $3 \%$. With fructose as the substrate, glucose was formed in less than 3\% yield, and with glucose as the substrate, fructose yield reached a maximum of ca. $16 \%$ at $61 \%$ conversion. These results suggest that, under the applied reaction conditions, the isomerisation of glucose to fructose is more important than the reverse reaction, in agreement with the literature [34,40]. Based on the kinetic profiles, the reactivity of fructose is higher than that of glucose, and fructose gives somewhat higher HMF yields, at least until ca. 75\% conversion. In the case of glucose, HMF may be formed from fructose (the isomerisation product), and this pathway may be in competition with major glucose degradation pathways [40-42]. Similar to that observed for xylose, for the hexoses, colour build-up was observed for the liquid phases and the catalyst, although no significant amounts of by-products were detected. FUR was always detected in minor amounts $(<2 \%$ yield at $6 \mathrm{~h}$ reaction of hexose), and may be formed via consecutive tautomerisation and retro-aldol reactions [40,42]. Levulinic acid (a possible product of the hydrolysis of HMF) was never detected, possibly because the acid sites of Al-TUD-1 are not strong enough: more 
acidic conditions are required for converting HMF into levulinic acid than for HMF formation [43]. According to the literature, HMF may be involved in the formation of coke deposits on the microporous surface of aluminosilicates [44]. Taking into consideration that polymerization reactions may be enhanced under relatively weak acidic conditions [43], and that Al-TUD-1 possesses mainly Lewis acid sites and weak Brønsted acidity, it is possible that by-products are essentially soluble polymers.

Figure 8. Reaction of glucose (A: $(\boldsymbol{\Delta})$ conversion; $(\bullet)$ fructose yield), and reaction of fructose $\left(\mathrm{B}\right.$ : $(\bullet)$ conversion; $(\boldsymbol{\Delta})$ glucose yield), in the presence of Al-TUD-1 at $170{ }^{\circ} \mathrm{C}$. The HMF $(\square),(-)$ mannose and FUR $(\times)$ yields are also shown.
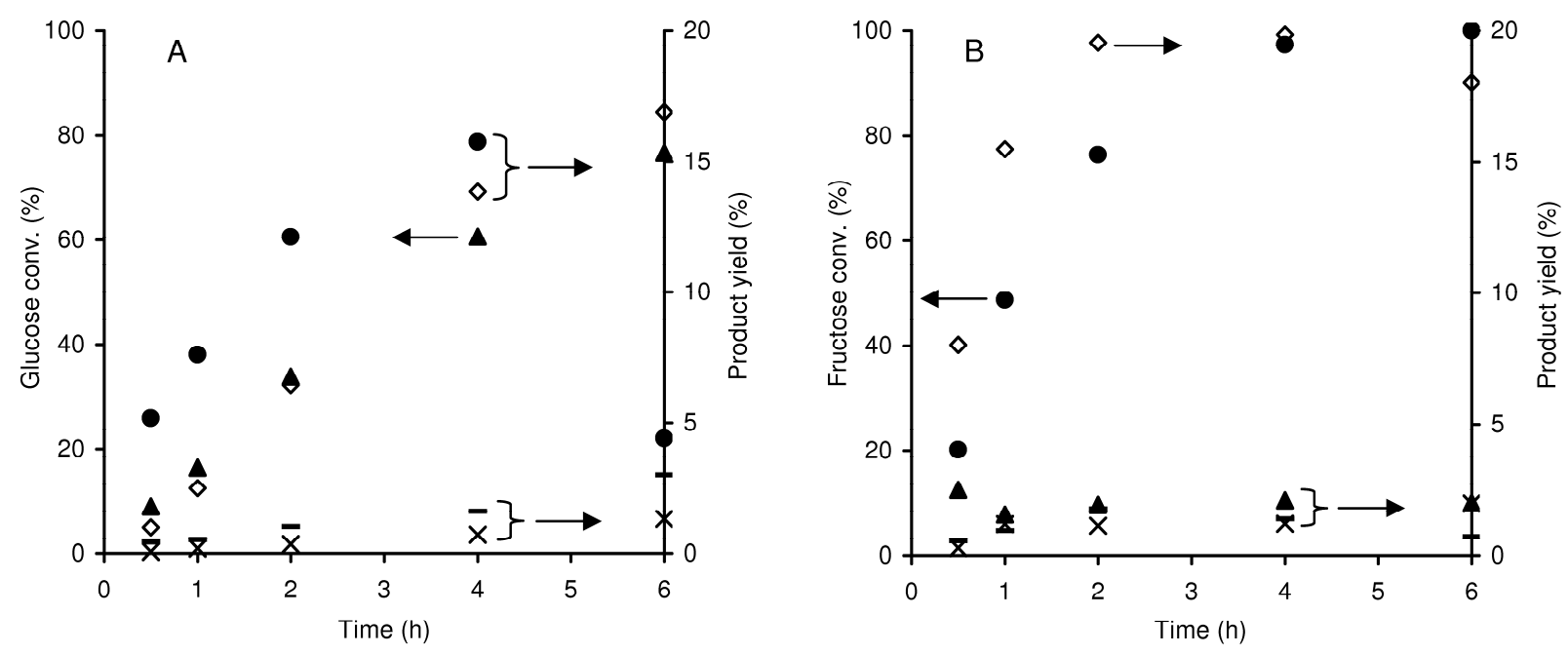

Somewhat in parallel with those observed for Al-TUD-1, the published results for microporous zeolites used as solid acids in the conversion of hexoses into HMF seem better for fructose than for glucose as substrate. The reaction of glucose in the presence of zeolite $\mathrm{H}-\mathrm{Y}(\mathrm{Si} / \mathrm{Al}=6.5)$ gave less than $10 \% \mathrm{HMF}$ yield at $\mathrm{ca} .75 \%$ conversion, at $160{ }^{\circ} \mathrm{C}$ [44]. In contrast, the reaction of fructose in the presence of H-beta, H-ZSM-5, H-mordenite and H-faujasite zeolites with $\mathrm{Si} / \mathrm{Al}$ ratios in the range of 10-100 was quite selective towards HMF, with one of the best results being 91\% HMF selectivity at $76 \%$ conversion $[8,44]$. The $\mathrm{Si} / \mathrm{Al}$ ratio influenced the rate of the reaction of fructose into $\mathrm{HMF}$, most likely due to changes in the acid properties and/or the surface polarity of the catalyst.

The one-pot conversion of the disaccharides sucrose [glucose and fructose linked by a $\beta(1 \rightarrow 2)$ glycosidic bond] and cellobiose [two glucose units linked by a $\beta(1 \rightarrow 4)$ glycosidic bond] in the presence of Al-TUD-1 gave 100\% conversion at $1 \mathrm{~h}$ reaction and $98 \%$ conversion at $6 \mathrm{~h}$, respectively, indicating that sucrose is more reactive than cellobiose (Figure 9). A similar relation of substrate reactivity may be established for zeolite $\mathrm{H}-\mathrm{Y}(\mathrm{Si} / \mathrm{Al}=15)$ used as acid catalyst in the same reactions (monosaccharide yield $>88 \%$ ) $[45,46]$; the $\mathrm{Si} / \mathrm{Al}$ ratio may have an important effect on the hydrolysis reaction rate [47]. The reaction of sucrose in the presence of Al-TUD-1 gave glucose and fructose as the main products at $30 \mathrm{~min}$ reaction (formed in ca. $40 \%$ yield each), indicating that relatively fast hydrolysis takes place (Figure 9A). After 30 min reaction, the monosaccharide yields decrease, especially for fructose (consistent with the fructose reactivity being higher than that for glucose, referred to above), and a maximum HMF yield of $17 \%$ was reached. In the case of cellobiose, glucose 
is the main product at $6 \mathrm{~h}$ reaction ( $50 \%$ yield), fructose yield is $10 \%$, and HMF yield is $12 \%$ (Figure 9B). For both disaccharides minor amounts of mannose and FUR were formed during the $6 \mathrm{~h}$ reaction (as observed with fructose and glucose as feedstocks). The undesirable reaction pathways may be similar to those occurring for fructose and glucose (give a maximum HMF yield of $20 \%$ and $17 \%$, respectively).

Figure 9. Reaction of sucrose (A) and of cellobiose (B), in the presence of Al-TUD-1 at $170^{\circ} \mathrm{C}:\left(^{*}\right)$ disaccharide conversion; $(\bullet)$ fructose yield, $(\boldsymbol{\Delta})$ glucose yield; $(\square)$ HMF yield; (-) mannose yield; $(\times)$ FUR yield.
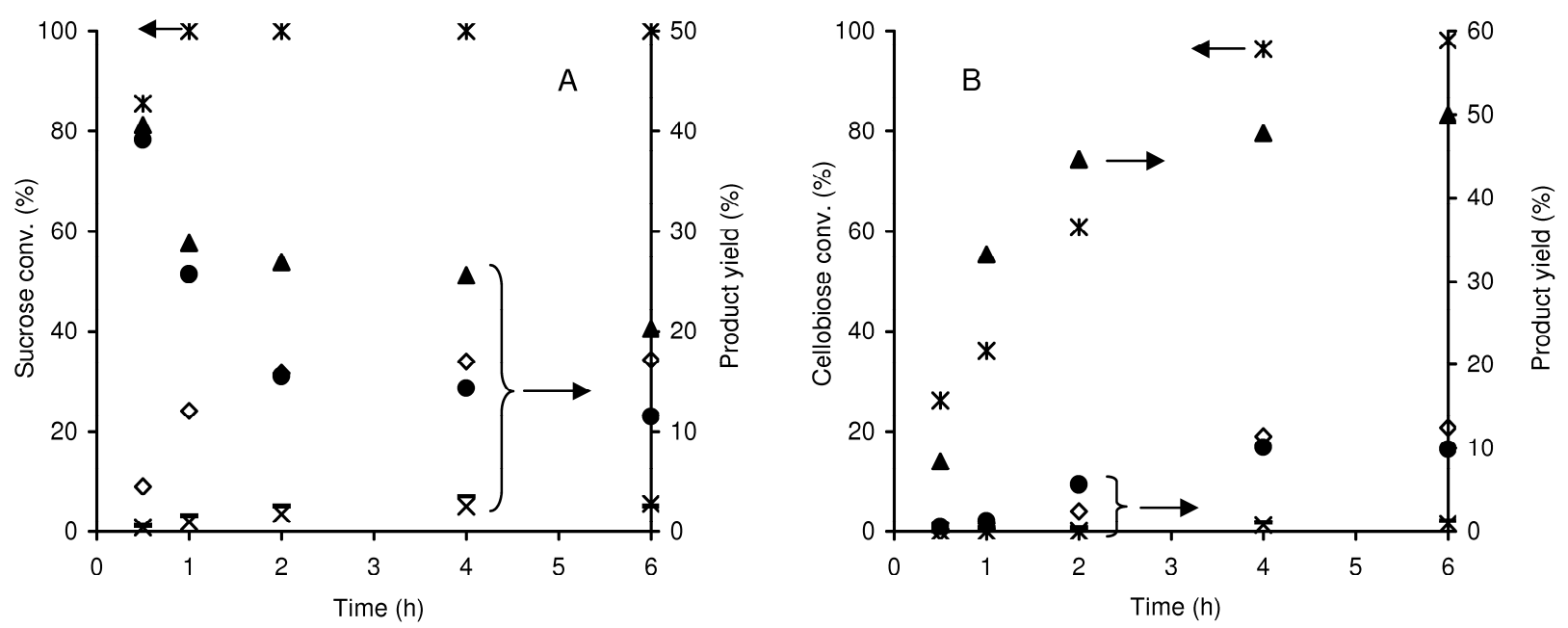

The one-pot conversion of inulin (a fructan, used in $10 \mathrm{wt} \%$ ) in the presence of Al-TUD-1 gave mainly fructose at $30 \mathrm{~min}$ reaction (67 wt \% yield), Figure 10.

Figure 10. Reaction of inulin in the presence of Al-TUD-1 at $170{ }^{\circ} \mathrm{C}$ : $(\bullet)$ fructose yield; ( $\Delta$ ) glucose yield; (-) mannose yield; ( $\square$ ) HMF yield.

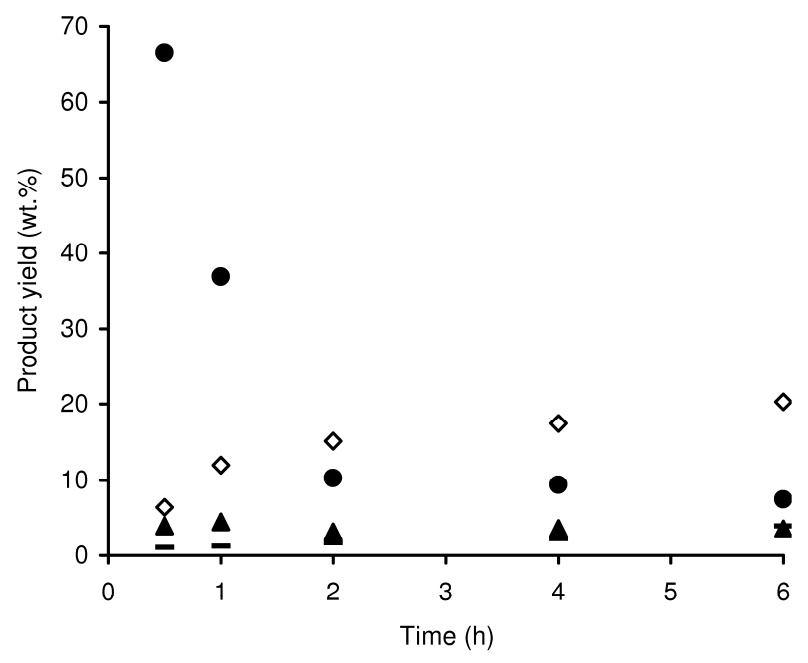

A fast drop in fructose yield with time was accompanied by the formation of HMF, reaching $20 \mathrm{wt} \%$ yield at $6 \mathrm{~h}$ (the theoretical yield is approximately $78 \mathrm{wt} \%$ ). Glucose and mannose were minor products formed via reversible isomerisation $(<5 \mathrm{wt} \%$ yield $)$. The selective hydrolysis of inulin 
(avoiding HMF formation) has been successfully carried out using H-Y zeolite at lower reaction temperatures (ca. $92 \%$ fructose yield, at $90{ }^{\circ} \mathrm{C}$ ) [46].

\section{Experimental}

\subsection{General}

All reagents, substrates, solvents and standards were obtained from commercial sources and used as received: aluminum(III) isopropoxide ( $\geq 99 \%)$, D-(+)-cellobiose ( $\geq 99 \%)$, inulin, D- $(+)$-sucrose ( $\geq 99 \%)$ and phenol ( $\geq 99.5 \%)$ from Fluka; isopropanol (99\%), ethanol (99\%), triethanolamine (99.9\%), tetraethylammonium hydroxide (99.9\%), D-(-)-fructose (>99\%) and D-(-)-ribose (98\%) from Aldrich; tetraethylorthosilicate (99.9\%) and 4-O-methyl-D-glucurono-D-xylan from Sigma; D-(+)-glucose (>99\%), D-xylose (99\%) and toluene ( $\geq 99.9 \%)$ from Sigma-Aldrich; D-(-)-mannitol (>99\%) from Riedel-de Haën.

ICP-AES measurements for Si and Al were carried out at the Central Laboratory for Analysis, University of Aveiro (by E. Soares and co-workers). The ${ }^{27} \mathrm{Al}$ magic-angle spinning (MAS) NMR spectrum was measured at $104.26 \mathrm{MHz}$ with a Bruker Avance 400 (9.4 T) spectrometer, using a contact time of $0.6 \mu \mathrm{s}$, a recycle delay of $0.8 \mathrm{~s}$, and a spinning rate of $15 \mathrm{kHz}$. Chemical shifts are quoted in ppm from $\mathrm{Al}\left(\mathrm{H}_{2} \mathrm{O}\right)_{6}{ }^{3+}$. Powder X-ray diffraction (XRD) data were collected at room temperature on a Philips X'Pert MPD diffractometer, equipped with an X'Celerator detector, a graphite monochromator ( $\mathrm{Cu}-\mathrm{K} \alpha \mathrm{X}$-radiation, $\lambda=1.54060 \AA$ ) and a flat-plate sample holder, in a Bragg-Brentano para-focusing optics configuration $(40 \mathrm{kV}, 50 \mathrm{~mA})$. Samples were step-scanned in $0.04^{\circ} 2 \theta$ steps with a counting time of $6 \mathrm{~s}$ per step. SEM was carried out on a Hitachi SU-70 UHR Schottky instrument. The BET specific surface area was estimated from $\mathrm{N}_{2}$ adsorption isotherm measured at $-196{ }^{\circ} \mathrm{C}$ using a Micromeritics ASAP 2010 instrument: the sample was outgassed at $350{ }^{\circ} \mathrm{C}$ under vacuum. The acid properties were measured using a Nexus-Thermo Nicolet FTIR instrument (64 scans and resolution of $4 \mathrm{~cm}^{-1}$ ) equipped with a specially designed cell, using selfsupported discs $\left(5-10 \mathrm{mg} \mathrm{cm}^{-2}\right)$ and pyridine as the basic probe molecule. After in situ outgassing at $450{ }^{\circ} \mathrm{C}$ for $3 \mathrm{~h}\left(10^{-6} \mathrm{mbar}\right)$, pyridine (99.99\%) was contacted with the sample at $150{ }^{\circ} \mathrm{C}$ for $10 \mathrm{~min}$ and then evacuated at 150 and $350^{\circ} \mathrm{C}(30 \mathrm{~min})$ under vacuum $\left(10^{-6} \mathrm{mbar}\right)$. The IR bands at $c a .1540$ and $1455 \mathrm{~cm}^{-1}$ are related to pyridine adsorbed on Brønsted (B) and Lewis (L) acid sites, respectively [33]. Thermogravimetric analysis (TGA) and differential scanning calorimetry (DSC) were carried out under air using Shimadzu TGA-50 and DSC-50 systems.

\subsection{Synthesis of Al-TUD-1}

Al-TUD-1 was prepared as described previously [20]. Briefly, tetraethylorthosilicate (17.3 g, $83.0 \mathrm{mmol})$ was added to aluminium(III) isopropoxide $(0.68 \mathrm{~g}, 3.33 \mathrm{mmol})$ dissolved in a mixture of isopropanol $(6.5 \mathrm{~mL})$ and ethanol $(6.5 \mathrm{~mL})$. After stirring for a few minutes, a mixture of triethanolamine $(12.51 \mathrm{~g}, 83.9 \mathrm{mmol})$ and water $(9.4 \mathrm{~g})$ was added, followed by addition of tetraethylammonium hydroxide $(35 \mathrm{wt} \%$ in water, $11.12 \mathrm{~mL}, 27.0 \mathrm{mmol}$ ) under vigorous stirring. The clear gel obtained was stirred at room temperature for $24 \mathrm{~h}$ and dried at $98{ }^{\circ} \mathrm{C}$ for $24 \mathrm{~h}$, followed by 
hydrothermal treatment in a Teflon-lined stainless steel autoclave at $180{ }^{\circ} \mathrm{C}$ for $8 \mathrm{~h}$. Finally, the solid was calcined at $600{ }^{\circ} \mathrm{C}$ in static air for $10 \mathrm{~h}$ with a temperature ramp of $1{ }^{\circ} \mathrm{C} \mathrm{min}^{-1}$.

\subsection{Catalytic experiments}

Batch catalytic experiments were performed under nitrogen in a tubular glass micro-reactor equipped with a valve for gas purging. In a typical procedure, mono/disaccharide $(30 \mathrm{mg}) \mathrm{or}$ polysaccharide $(10 \mathrm{mg})$, powdered catalyst $(20 \mathrm{mg}), \mathrm{H}_{2} \mathrm{O}(0.3 \mathrm{~mL})$ and toluene $(0.7 \mathrm{~mL})$ were poured into the reactor. The reaction mixtures were stirred magnetically at $700 \mathrm{rpm}$ and heated with a thermostatically controlled oil bath. Zero time was taken to be the instant the micro-reactor was immersed in the oil bath: individual experiments were performed for a given reaction time. The products present in the aqueous phase were analysed using a Knauer K-1001 HPLC pump, coupled to a Knauer 2300 differential refractive index detector (for sugars) and a Knauer 2600 UV detector ( $280 \mathrm{~nm}$, for FUR and HMF). For pentose-based feedstocks a PL Hi-Plex H $300 \mathrm{~mm} \times 7.7 \mathrm{~mm}$ (i.d.) ion exchange column (Polymer Laboratories Ltd., UK) was used: the mobile phase was $0.01 \mathrm{M} \mathrm{H}_{2} \mathrm{SO}_{4}$; flow rate $0.6 \mathrm{~mL} \mathrm{~min}{ }^{-1}$; column temperature $65^{\circ} \mathrm{C}$. In the case of hexose-based feedstocks, a PL HiPlex Ca $300 \mathrm{~mm} \times 7.7 \mathrm{~mm}$ (i.d.) ion exchange column (Polymer Laboratories Ltd., UK) was used: the mobile phase was freshly prepared distilled and deionized water; flow rate $0.5 \mathrm{~mL} \mathrm{~min}{ }^{-1}$; column temperature $80{ }^{\circ} \mathrm{C}$. The products present in the organic phase were quantified using a Gilson 306 HPLC pump and a Spherisorb ODS S10 C18 column, coupled to a Gilson 118 UV-vis detector $(280 \mathrm{~nm})$. The mobile phase consisted of $30 \%(\mathrm{v} / \mathrm{v})$ methanol in an aqueous solution with $10 \%$ methanol (flow rate $0.7 \mathrm{~mL} \mathrm{~min}^{-1}$ ). Authentic samples of reagents and products were used as standards for measuring calibration curves. Conversion (\%) was calculated as $100 \times($ moles of substrate consumed)/(initial moles of substrate). For monosaccharides, FUR or HMF yields (mol \%) were calculated as $100 \times($ moles FUR or HMF formed)/(initial moles of monosaccharide). For disaccharides, HMF or monosaccharide yields (mol \%) were calculated as $100 \times($ moles of product formed)/(2×(initial moles of disaccharide)). In the case of the polysaccharides, the FUR or HMF yields (wt \%) were calculated as $100 \times($ mass of product formed)/(initial mass of polysaccharide). In order to check the data, the experiments were carried out in duplicate and the mean values were calculated.

\section{Conclusions}

The reaction of pentoses (xylose) and hexoses (glucose and fructose) in the presence of Al-TUD-1, at $170{ }^{\circ} \mathrm{C}$, gave FUR and HMF, respectively; the reactions of hexoses gave 17-20\% HMF yields at $6 \mathrm{~h}$, and the reaction of xylose gave $60 \%$ FUR yield. Possibly, the acid properties of Al-TUD-1 (mainly Lewis acid sites and weak Brønsted acidity) are more favourable for converting xylose into FUR than hexoses into HMF. The one-pot hydrolysis/dehydration of sucrose and cellobiose in the presence of Al-TUD-1 gave the monosaccharides via the hydrolysis of the glycosidic bonds, which are subsequently dehydrated into HMF, obtained in $17 \%$ and $12 \%$ yield from sucrose and cellobiose, respectively. In the case of the polysaccharides, xylan and inulin, FUR and HMF were formed in 18 and $20 \mathrm{wt} \%$ yield at $6 \mathrm{~h}$, respectively. Based on the colour build-up of the solvents (colourless-yelloworange) and of the catalyst (white-brown-black) during the course of the reactions, and the fact that no 
significant amounts of by-products were detected, it is postulated that the formation of soluble polymers and coke deposits may be important competitive reactions, affecting FUR and HMF yields.

Based on the catalytic results for four consecutive $6 \mathrm{~h}$ batches carried out for the reaction of xylose, Al-TUD-1 seems to be a fairly stable catalyst. FUR yields at $6 \mathrm{~h}$ were in the range 56-60\%. The catalytic performance of Al-TUD-1 may be improved by fine-tuning the acid properties (varying the $\mathrm{Si} / \mathrm{Al}$ ratio [49]) and optimising the reaction conditions.

\section{Acknowledgements}

This work was partly funded by the Portuguese Science Foundation (FCT), POCTI and FEDER (project POCTI/QUI/56112/2004 and PTDC/QUI/71198/2006). The authors thank C.P. Neto for helpful discussions and F. Domingues for access to HPLC equipment. S.L. and M.M.A. are grateful to the FCT for grants.

\section{References and Notes}

1. Román-Leshkov, Y.; Chheda, J.N.; Dumesic, J.A. Phase Modifiers Promote Efficient Production of Hydroxymethylfurfural from Fructose. Science 2006, 312, 1933-1937.

2. Chheda, J.N.; Román-Leshkov, Y.; Dumesic, J.A. Production of 5-hydroxymethylfurfural and furfural by dehydration of biomass-derived mono- and poly-saccharides. Green Chem. 2007, 9, $342-350$.

3. Briens, C.; Piskorz, J.; Berruti, F. Biomass Valorization for Fuel and Chemicals Production - A Review. Int. J. Chem. Reactor Eng. 2008, 6, 1-49.

4. Huber, G.W.; Iborra, S.; Corma, A. Synthesis of transportation fuels from biomass: Chemistry, Catalysts, and Engineering. Chem. Rev. 2006, 106, 4044-4098.

5. Zeitsch, K.J. The chemistry and technology of furfural and its many by-products. In Sugar Series, 1st ed.; Elsevier: Amsterdam, The Netherlands, 2000; Volume 13.

6. Mamman, A.S.; Lee, J.-M.; Kim, Y.-C.; Hwang, I.T.; Park, N.-J.; Hwang, Y.K.; Chang, J.-S.; Hwang, J.-S. Furfural: Hemicellulose/xylose-derived biochemical. Biofuels, Bioprod. Bioref. 2008, 2, 438-454.

7. Lourvanij, K.; Rorrer, G.L. Reactions of aqueous glucose solutions over solid-acid Y-zeolite catalyst at 110-160 ${ }^{\circ} \mathrm{C}$. Ind. Eng. Chem. Res. 1993, 32, 11-19.

8. Moreau, C.; Durand, R.; Pourcheron, C.; Razigade, S. Preparation of 5-hydroxymethylfurfural from fructose and precursors over H-form zeolites. Ind. Crops Prod. 1994, 3, 85-90.

9. Moreau, C. Zeolites and related materials for the food and non food transformation of carbohydrates. Agro-Food Ind. Hi-Tech. 2002, 13, 17-26.

10. Dias, A.S.; Lima, S.; Brandão, P.; Pillinger, M.; Rocha, J.; Valente, A.A. Liquid-phase dehydration of D-xylose over microporous and mesoporous niobium silicates. Catal. Lett. 2006, 108, 179-186.

11. Lima, S.; Fernandes, A.; Antunes, M.M.; Pillinger, M.; Ribeiro, F.; Valente, A.A. Dehydration of xylose into furfural in the presence of crystalline microporous silicoaluminophosphates. Catal. Lett. 2010, 135, 41-47. 
12. Carlini, C.; Patrono, P.; Galletti, A.M.R.; Sbrana, G. Heterogeneous catalysts based on vanadyl phosphate for fructose dehydration to 5-hydroxymethyl-2-furaldehyde. Appl. Catal. A: General 2004, 275, 111-118.

13. Dias, A.S.; Lima, S.; Carriazo, D.; Rives, V.; Pillinger, M.; Valente, A.A. Exfoliated titanate, niobate and titanoniobate nanosheets as solid acid catalysts for the liquid-phase dehydration of Dxylose into furfural. J. Catal. 2006, 244, 230-237.

14. Rinaldi, R.; Schüth, F. Design of solid catalysts for the conversion of biomass. Energy Environ. Sci. 2009, 2, 610-626.

15. Dias, A.S.; Lima, S.; Pillinger, M.; Valente, A.A. Furfural and Furfural-Based IndustrialChemicals. In Ideas in Chemistry and Molecular Sciences: Advances in Synthetic Chemistry; Pignataro, B., Ed.; Wiley-VCH: Weinheim, Germany, 2010; pp. 167-186.

16. Netrabukkana, R.; Lourvanij, K.; Rorrer, G.L. Diffusion of glucose and glucitol in microporous and mesoporous silicate aluminosilicate catalysts. Ind. Eng. Chem. Res. 1996, 35, 458-464.

17. Kresge, C.T.; Leonowicz, M.E.; Roth, W.J.; Vartuli, J.C.; Beck, J.S. Ordered mesoporous molecular sieves synthesized by a liquid-crystal template mechanism. Nature 1992, 359, 710-712.

18. Telalović, S.; Ramanathan, A.; Mul, G.; Hanefeld, U. TUD-1: synthesis and application of a versatile catalyst, carrier, material. J. Mater. Chem. 2010, 20, 642-658, and references cited therein.

19. Shan, Z.; Jansen, J.C.; Zhou, W.; Maschmeyer, Th. Al-TUD-1, stable mesoporous aluminas with high surface areas. Appl. Catal. A: General 2003, 254, 339-343.

20. Simons, C.; Hanefeld, U.; Arends, I.W.C.E.; Sheldon, R.A.; Maschmeyer, T. Noncovalent anchoring of asymmetric hydrogenation catalysts on a new mesoporous aluminosilicate: application and solvent effects. Chem. Eur. J. 2004, 10, 5829-5835.

21. Anand, R.; Maheswari, R.; Hanefeld, U. Catalytic properties of the novel mesoporous aluminosilicate AlTUD-1. J. Catal. 2006, 242, 82-91.

22. Zhang, Z.-X.; Bai, P.; Xu, B.; Yan, Z.F. Synthesis of mesoporous alumina TUD-1 with high thermostability. J. Porous Mater. 2006, 13, 245-250.

23. Telalović, S.; Ng, J.F.; Maheswari, R.; Ramanathan, A.; Chuah, G.K.; Hanefeld, U. Synergy between Brønsted acid sites and Lewis acid sites. Chem. Commun. 2008, 4631-4633.

24. Telalović, S.; Hanefeld, U. Noncovalent immobilization of chiral cyclopropanation catalysts on mesoporous TUD-1: Comparison of liquid-phase and gas-phase ion-exchange. Appl. Catal. A: Chem. 2010, 372, 217-223.

25. Jansen, J.C.; Shan, Z.; Marchese, L.; Zhou, W.; Puil, N.v.d.; Maschmeyer, Th. A new templating method for three-dimensional mesopore networks. Chem. Commun. 2001, 713-714.

26. Sing, K.S.W. Characterization of adsorbents. In Adsorption, Science and Technology; Rodrigues, A.E., LeVan, M.D., Tondeur, D., Eds.; Kluwer Academic Publishers: Dordrecht, The Netherlands, 1989; pp. 3-14.

27. Sangwichien, C.; Aranovich, G.L.; Donohue, M.D. Density functional theory predictions of adsorption isotherms with hysteresis loops. Colloids Surf., A 2002, 206, 313-320.

28. Blin, J.L.; Léonard, A.; Su, B.L. Well-ordered spherical mesoporous materials CMI-1 synthesized via an assembly of decaoxyethylene cetyl ether and TMOS. Chem. Mater. 2001, 13, 3542-3553. 
29. Shan, Z.; Jansen, J.C.; Marchese, L.; Maschmeyer, Th. Synthesis, characterization and catalytic testing of a 3-D mesoporous titanosilica, Ti-TUD-1. Microporous Mesoporous Mater. 2001, 48, 181-187.

30. Zhou, J.; Hua, Z.; Shi, J.; He, Q.; Guo, L.; Ruan, M. Synthesis of a hierarchical micro/mesoporous structure by steam-assisted post-crystallization. Chem. Eur. J. 2009, 15, 12949-12954.

31. Webster, C.E.; Drago, R.S.; Zerner, M.C. Molecular dimensions for adsorptives. J. Am. Chem. Soc. 1998, 120, 5509-5516.

32. Luan, Z.; Fournier, J.A. In situ FTIR spectroscopic investigation of active sites and adsorbate interactions in mesoporous aluminosilicate SBA-15 molecular sieves. Microporous Mesoporous Mater. 2005, 79, 235-240.

33. Gallo, J.M.R.; Bisio, C.; Gatti, G.; Marchese, L.; Pastore, H.O. Physicochemical characterization and surface acid properties of mesoporous [Al]-SBA-15 obtained by direct synthesis. Langmuir 2010, 26, 5791-5800.

34. Van-Bekkum, H.E.; Kieboom, A.P.G.; Van-Bekkum, H. The conversion of fructose and glucose in acid media. Formation of hydroxymethylfurfural. Starch/Stärke 1986, 95-101, and references therein.

35. Moreau, C.; Durand, R.; Peyron, D.; Duhamet, J.; Rivalier, P. Selective preparation of furfural from xylose over microporous solid acid catalysts. Ind. Crops Prod. 1998, 7, 95-99.

36. Lichenthaler, F.W. The key sugars of biomass: Availability, non-food uses and future development lines. In Biorefineries - Industrial Processes and Products: Status Quo and Future Directions; Kamm, B., Grober, P.R., Kamm, M., Eds.; Wiley-VCH: New York, NY, USA, 2006; Volume 2, pp. 3-59.

37. Moreau, C.; Belgacem, M.N.; Gandini, A. Recent catalytic advances in the chemistry of substituted furans from carbohydrates and in the ensuing polymers. Top. Catal. 2004, 27, $11-30$.

38. Lima, S.; Pillinger, M.; Valente, A.A. Dehydration of D-xylose into furfural catalysed by solid acids derived from the layered zeolite Nu-6(1). Catal. Commun. 2008, 9, 2144-2148.

39. Antal, M.J.; Leesomboon, T.; Mok, W.S.; Richards, G.N. Mechanism of formation of 2furaldehyde from D-xylose. Carbohydr. Res. 1991, 217, 71-85.

40. Asghari, F.S.; Yoshida, H. Acid-Catalyzed Production of 5-hydroxymethylfurfural from Dfructose in subcritical water. Ind. Eng. Chem. Res. 2006, 45, 2163-2173.

41. Antal, M.J.; Mok, W.S.L. Kinetic studies of the reactions of ketoses and aldoses in water at high temperature. 1. Mechanism of formation of 5-(hydroxymethyl)-2-furaldehyde from D-fructose and sucrose. Carbohydr. Res. 1990, 199, 91-109.

42. Aida, T.M.; Sato, Y.; Watanabe, M.; Tajima, K.; Nonaka, T.; Hattori, H.; Arai, K. Dehydration of D-glucose in high temperature water at pressures up to $80 \mathrm{MPa}$. J. Supercrit. Fluids 1997, 40, 381-388.

43. Kuster, F.M.; Temmink, H.M.G. The influence of $\mathrm{pH}$ and weak acid anions on the dehydration of D-fructose. Carbohydr. Res. 1977, 54, 185-191.

44. Moreau, C.; Durand, R.; Razigade, S.; Duhamet, J.; Faugeras, P.; Rivalier, P.; Ross, P.; Avignon, G. Dehydration of fructose to 5-hydroxymethylfurfural over H-Mordenites. Appl. Catal. A: General 1996, 145, 211-224. 
45. Moreau, C.; Durand, R.; Duhamet, J.; Rivalier, P. Hydrolysis of fructose and glucose precursors in the presence of H-form zeolites. J. Carbohydr. Chem. 1997, 16, 709-714.

46. Moreau, C.; Durand, R.; Aliès F.; Cotillon, M.; Frutz, T.; Théoleyre, M.-A. Hydrolysis of sucrose in the presence of H-form zeolites. Ind. Crops Prod. 2000, 11, 237-242.

47. Buttersack, C.; Laketic, D. Hydrolysis of sucrose by dealuminated Y-zeolites. J. Mol. Catal. 1994, 94, L283-L290.

48. Campelo, J.M.; Lafont, F.; Marinas, J.M. Pt/SAPO-5 and Pt/SAPO-11 as Catalysts for the Hydroisomerization and Hydrocracking of n-Octane. J. Chem. Soc. Faraday Trans. 1995, 91, 1551-1555.

49. Anand, R.; Maheswari, R.; Hanefeld, U. Catalytic properties of the novel mesoporous aluminosilicate AlTUD-1. J. Catal. 2006, 242, 82-91.

Sample Availability: Small quantities of the catalyst Al-TUD-1 are available from the authors on request.

(C) 2010 by the authors; licensee MDPI, Basel, Switzerland. This article is an Open Access article distributed under the terms and conditions of the Creative Commons Attribution license (http://creativecommons.org/licenses/by/3.0/). 